\title{
Emerging Role of MicroRNAs in Drug-Resistant Breast Cancer
}

\author{
SARMILA MAJUMDER AND SAMSON T. JACOB
}

Department of Molecular and Cellular Biochemistry, College of Medicine, Comprehensive Cancer Center, The Ohio State University, Columbus, OH, USA

Intrinsic or acquired resistance to commonly used therapeutic agents is a major challenge in treating cancer patients. Decades of research have unraveled several unique and common mechanisms that could contribute to drug resistance in breast cancer. Recent studies unraveled the regulatory role of small noncoding RNA, designated as microRNA (miRNA), that were thought to be "junk" RNA in the past. Practically all aspects of cell physiology under normal and disease conditions were found to be regulated by miRNAs. In this review, we will discuss how miRNA profile is altered upon resistance development and the critical regulatory role miRNAs play in conferring resistance to commonly used therapeutic agents. It is hoped that further studies will lead to use of these differentially expressed miRNAs as prognostic and predictive markers, as well as novel therapeutic targets to overcome resistance.

Key words: Breast cancer; Drug resistance; MicroRNAs

\section{INTRODUCTION}

Breast cancer is the most common malignant tumor in women, accounting for $31 \%$ of all female cancers worldwide. It is one of the leading causes of cancer-related deaths among women in the Western world despite better screening, early detection, and advent of targeted therapies. Although chemotherapy improves survival rates in the adjuvant setting, around $50 \%$ of all treated patients will relapse (37). The major reason for therapeutic failure is the development of resistance against current therapeutic agents. It is increasingly evident that drug-resistant mammary carcinoma cells are generated by prolonged exposure to the antineoplastic agents. It is also likely that such resistant cells are already present in the tumor before treatment that evade the therapy and facilitates relapse.

Drug-resistant tumors are best described by their ability to undergo epithelial to mesenchymal transition (EMT) and enrichment of tumor-initiating cells (TIC) that results in a highly aggressive tumor usually after prolonged dormancy. Recent studies have demonstrated strong evidences that microRNAs (miRNAs) could regulate both EMT [reviewed in (88)] and formation of cancer-initiating cells [reviewed in (33)]. Further, constantly evolving concept about TICs suggests that non-TICs could regenerate to TICs and repopulate the tumor after effective therapeutic targeting of the TICs in the primary tumor. This could lead to renewed tumor growth after completion of the therapy (35). Considering the ubiquitous role of miRNAs in regulating numerous cellular pathways, it is highly likely that miRNAs play a key role in this transition as well and contribute to development of resistance. Considerable effort therefore has been made to understand the role of miRNAs in conferring drug resistance in different types of cancers in the last few years.

A significant fraction of the genes in all organisms do not encode proteins, but code for a diverse group of noncoding RNAs. One class of small noncoding RNA genes produce exceedingly short transcripts of about 22 nucleotides in length from characteristic hairpin precursors. These small RNAs, designated miRNAs (or miRs) can either cleave mature mRNA

Address correspondence to Sarmila Majumder, Department of Molecular and Cellular Biochemistry, College of Medicine, Comprehensive Cancer Center, The Ohio State University, Columbus, OH 43210, USA. Tel: 614-292-0103; E-mail: Sarmila.Majumder@osumc.edu 
molecules or inhibit their translation through imperfect base-pairing predominantly with 3'-UTR of protein coding genes, thereby fine tuning the expression of the protein. Currently, there are 1,733 miRNAs (48), and about one third of all human genes appear to be targeted by miRNAs. Research spanning over a decade has shown that these small RNAs can regulate almost all aspects of cell physiology under normal as well as disease conditions (4).

\section{miRNA BIOGENESIS}

miRNAs are mostly transcribed by RNA polymerase II as approximately $1-3 \mathrm{~kb}$ long primary transcripts from intragenic or intergenic regions of protein coding genes $(52,76)$. These primary transcripts called pri-miRNAs are further processed to about 70-100 nucleotides hairpin pre-miRNA by the ribonuclease Drosha and DiGeorge syndrome critical region gene 8 (DGCR8) complex in the nucleus (50, 51). The pre-miRNA is then transported with the help of exportin 5 to the cytoplasm (9) where it undergoes further processing by the ribonuclease Dicer into a mature double-stranded miRNA (36). A single strand of the miRNA duplex is incorporated into a ribonucleoprotein effector complex also known as the RNA-induced silencing complex (RISC) $(36,61)$. Based on complementarities between the guide RNA and the mRNA, RISC identifies target messages and leads to either endonucleolytic cleavage of targeted mRNA or translational repression (5,57). Further, Argonaute proteins (argonaute 1-argonaute 4), the protein factors comprising RISC, play a critical role in miRNA biogenesis, maturation, and miRNA effector functions $(6,16,39)$.

\section{MECHANISMS OF DRUG RESISTANCE}

Breast cancer is a heterogeneous disease that is treated with different drug regimens. Development of resistance to current treatment options is the major challenge in curing this disease. Over the last three decades, extensive studies have unraveled mechanisms underlying drug resistance and disease relapse [reviewed in (49)] and several hypotheses have been suggested for the mechanisms of drug resistance. While clonal selection and subsequent expansion of cells that failed treatment was the central hypothesis in the 1970-1980 period (69), tumor dormancy through restricted angiogenic activity (85) was popular in the 1990s. The most recent hypothesis is drug-induced selection of TICs that leads to disease relapse and metastasis (74). It is believed that each of these mechanisms contributes to resistance development in breast cancer, making it increasingly harder to overcome. Extensive research has identified several cell cycle regulatory genes, prosurvival genes, proapoptotic genes, and chemokines that are deregulated during development of drug resistance $(58,67,71)$. Recent studies, including our own, have demonstrated a role of miRNAs in differential gene expression leading to resistance. The potential role of specific miRNAs in the loss of sensitivity to drugs, particular to anticancer agents, offers a novel mechanism for acquiring resistance to most widely used drugs in cancer therapy. The involvement of different miRNAs in conferring resistance to treatment of breast cancer is discussed in detail in the next section and is summarized in Table 1.

\section{miRNAs IN ENDOCRINE RESISTANCE}

\section{Tamoxifen}

Approximately two thirds of all invasive breast cancers are estrogen (ER) or progesterone receptor (PR) positive, including at least half of all cancers in premenopausal women. Selective estrogen receptor modulators (SERMs) or selective estrogen receptor downregulators (SERDs) and aromatase inhibitors are the two broad groups of currently approved antiestrogen therapies (41). As the name implies, SERM and SERD blocks function of ER whereas aromatase inhibitors interfere with estrogen production in postmenopausal women. Tamoxifen is a nonsteroidal triphenylethylene derivative that binds to the estrogen receptor and blocks estrogen signaling in mammary epithelium (42). There is evidence that tamoxifen also interferes with several other signaling pathways: IGF-1 (22), TGF- $\beta$, etc. $(13,43)$. The Early Breast Cancer Trialists' Collaborative Group demonstrated a significant improvement in 15-year survival with the addition of adjuvant tamoxifen for 5 years following surgery (24). Further, tamoxifen can also reduce the incidence of contralateral breast cancer and has been approved as a prophylactic agent to prevent breast cancer. Tamoxifen (SERM) is the only agent approved for younger, premenopausal women with breast cancer for the treatment of ER-positive DCIS and as a chemopreventive agent. Fulvestrant (SERD) is used to treat postmenopausal women with ER-positive metastatic breast cancer when other treatments (e.g., tamoxifen) have failed. Despite this accomplishment in the management of women with potentially endocrine-responsive breast cancers, a significant proportion of these women will experience disease progression secondary to an inherently intrinsic or acquired resistance to endocrine agents (55).

Our study using tamoxifen-resistant and -sensitive 
TABLE 1

SUMMARY OF MicroRNAS INVOLVED IN DRUG RESISTANCE IN BREAST CANCER

\begin{tabular}{|c|c|c|c|c|}
\hline $\begin{array}{l}\text { Chemotherapeutic } \\
\text { Agent }\end{array}$ & MicroRNA & $\begin{array}{c}\text { Up-/ } \\
\text { Downregulation }\end{array}$ & Potential Target Genes & Reference(s) \\
\hline Tamoxifen & $\begin{array}{l}\text { miR-221, miR-222, miR-181 } \\
\text { miR-221, miR-222 } \\
\text { miR-21, miR-342, miR-489 } \\
\text { miR-342 } \\
\text { miR-451 }\end{array}$ & $\begin{array}{l}\uparrow \\
\uparrow \\
\downarrow \\
\downarrow \\
\downarrow\end{array}$ & $\begin{array}{l}\text { p27(Kip1), TIMP3 } \\
E R \alpha \\
\text { BMP-7, Gemin4, SEMAD3 } \\
14-3-3 \zeta\end{array}$ & $\begin{array}{c}64 \\
91 \\
64 \\
21 \\
7\end{array}$ \\
\hline $\begin{array}{l}\text { Tamoxifen }+ \\
\text { exemestane }\end{array}$ & $\begin{array}{l}\text { miR-21, miR-181b, miR-26a, } \\
\text { miR-26b, miR-27b, miR-23b }\end{array}$ & $\downarrow$ & & 59 \\
\hline $\begin{array}{l}\text { Tamoxifen }+ \\
\text { exemestane }\end{array}$ & miR-200c & $\uparrow$ & & 59 \\
\hline $\begin{array}{l}\text { Tamoxifen + } \\
\text { radiation }\end{array}$ & $\operatorname{miR}-301$ & $\uparrow$ & FOXF2, PUMA, PTEN, COL2A1 & 79 \\
\hline Fulvestrant & miR-221, miR-222 & $\uparrow$ & multiple oncogenic signaling pathways & 75,89 \\
\hline Trastuzumab & $\operatorname{miR}-342$ & $\downarrow$ & BMP-7, Gemin4, SEMAD3 & 21 \\
\hline Letrozole & miR-128a & $\uparrow$ & $T G B R 1$ & 62 \\
\hline Doxorubicin & $\begin{array}{l}\text { miR-127, miR-200a, miR-200c, } \\
\text { miR-34a, miR-15a, miR-16, } \\
\text { miR-27b, let-7 }\end{array}$ & $\downarrow$ & BCL6, TCF8, E2F3 \& Notch1, CYP1B,K-RAS & 47 \\
\hline Doxorubicin & $\begin{array}{l}\text { miR-21, miR-28, miR-106a, } \\
\text { miR-206 }\end{array}$ & $\uparrow$ & RB1, PTEN, ER $\alpha, B R C A 1$ & 47 \\
\hline Cisplatin & miR-146a, miR-10a, miR-221/222 & $\uparrow$ & & 73 \\
\hline Cisplatin & $\begin{array}{l}\text { miR-345, miR-200c, miR-126, } \\
\quad \text { miR-127 }\end{array}$ & $\downarrow$ & $Z E B 1 / 2, M R P 1$ & 73 \\
\hline $\begin{array}{l}\text { Paclitaxal, } \\
\text { doxorubicin, } \\
\text { VP16 }\end{array}$ & miR-155 & $\uparrow$ & FOXO3a & 44 \\
\hline
\end{tabular}

human breast adenocarcinoma cell lines (MCF-7) showed increased expression of miR-221, miR-222, miR-181b, and downregulation of miR-21, miR-342, and miR-489 in the tamoxifen-resistant cells. Expression of miR-221, miR-222, and miR-181b was also significantly elevated in HER2/neu-positive primary human breast cancer that is known to exhibit relatively high level of resistance to endocrine therapy (64). The level of cell cycle inhibitor p27(Kip1), one of the targets of miR-221/222, was significantly diminished in tamoxifen-resistant cells. While posttranslational modification and sequestration of p27(Kip1) in the cytoplasm contribute to tamoxifen resistance in breast cancer (8), miRNA-mediated suppression of p27(Kip1) could be additional mechanism by which cells lose sensitivity to tamoxifen. Another laboratory (91) demonstrated that miR-221 and miR-222 overexpression in ER-positive cells suppresses ER $\alpha$ expression at the protein level. Although both studies showed that ectopic expression of miR-221/222 renders the parental MCF-7 cells resistant to tamoxifen $(64,91), E R \alpha$ protein is stabilized in the resistant MCF-7 cells generated upon long-term exposure to tamoxifen, as opposed to transient overexpression of miR-221/222 (S. Majumder, unpublished data). An interesting observation was that the tissue metalloprotease inhibitor TIMP3 is targeted by miR-221, miR222 , and $\mathrm{miR}-181 \mathrm{~b}$, thereby facilitating the growth factor signaling in the tamoxifen-resistant cells ( $\mathrm{S}$. Majumder, unpublished data).

A few miRNAs are also significantly downregulated in the tamoxifen-resistant cells. Our microarray analysis revealed that miR-342, miR-489, and miR21 are few of the several miRNAs diminished in the tamoxifen-resistant cells (64). A recent study demonstrated that miR-342 expression was drastically reduced in Her $2 \Delta 16$ (oncogenic splice isoform of HER2) overexpressing MCF-7 cells that are resistant to both endocrine therapy $(21,68)$ and to trastuzumab $(65)$. MiR-342 expression was also markedly curtailed in two other MCF-7 variants resistant to tamoxifen when treated with 17- $\beta$-estradiol (E2) and 4-hydroxytamoxifen (20). A similar trend of miR-342 downregulation was also observed in 16 ER-positive primary breast tumors from patients who underwent tamoxifen treatment. Six patients in this group developed 
recurrences and distant metastasis. BMP-7, and Gemin 4 were identified as the direct targets of miR-342 in the MCF-7/ Her $2 \Delta 16$ cells (21).

MiR-24, miR-27, miR-23, and miR-200 were also downregulated in the tamoxifen-resistant cells. Similarly, we also observed increased expression of miR375, miR-171, miR-213, miR-203, and miR-32 in the drug-resistant cells (64). Further exploration of the role of these miRNAs in conferring resistance to tamoxifen is warranted. This will require identification of their target mRNAs and understanding the functional relevance of altered levels of the corresponding proteins. An important question is whether alteration in the levels of a distinct protein or a class of proteins resulting from upregulation or downregulation of specific miRNAs plays a direct role in conferring resistance to tamoxifen. In this context, it is of interest that a recent study has demonstrated relatively low level of miR-451 in tamoxifen-resistant cells compared to parental MCF-7 cells and higher expression of 14-3-3 $\zeta$, a target of this miRNA (7). The 14-33 proteins constitute a family of highly conserved, ubiquitously expressed dimeric proteins (2). These noncatalytic proteins forms protein complexes with other signaling molecules, like Bad and FOXO/Forkhead, etc., and exert their effect by modulating subcellular localization or catalytic activity of target proteins (83). Remarkably, higher expression of 14-3-3ל that promotes cell survival by inhibiting apoptosis correlates significantly with disease recurrence and is a marker of poor prognosis in ER-positive women treated with tamoxifen (29).

A recent analysis of tumors from patients $(n=15)$ receiving a combination of exemestane (an inhibitor of CYP19 aromatases, enzymes catalyzing the last steps of estrogen biosynthesis) and tamoxifen daily as a neoadjuvant therapy, for 4 months demonstrated increased expression of miR-21, miR-181b, miR-26a, miR-26b, miR-27b, miR-23b, and reduction in miR200c expression compared to the pretreatment tumor biopsy samples (59). Some of these miRNAs are common to the deregulated miRNAs identified in resistant cell lines, suggesting that the drug-induced alteration in miRNA expression could be an early yet a long drawn out process. A recent case control study with 71 patients treated with tamoxifen or tamoxifen plus radiation, reported direct association of miR-301 expression with distant metastasis (79). These patients were classified into two groups. One group $(n=33)$ had experienced local, lymph node, or distant metastasis within 10 years whereas the other group $(n=38)$ did not exhibit any relapse or death from cancer in $>10$ years' follow-up. This study identified FOXF2, BBC3 (PUMA), PTEN, and COL2A1 as direct targets of miR-301. Altered levels of these proteins could potentially affect cell proliferation, invasion, migration, and angiogenesis. The disparities among the miRNAs that are differentially regulated in tamoxifen-resistant breast cancer could be attributed to overall genetic variation from patient to patient.

\section{Fulvestrant}

Fulvestrant is another commonly used antiestrogenic compound in patients with advanced breast cancer who have failed prior endocrine therapy. Fulvestrant a 7alkylsulphinyl analogue of 17-estradiol, competitively inhibits binding of estradiol to the ER, blocks receptor dimerization, nuclear localization, where ER acts as a transcription factor. This leads to rapid degradation of the ER/fulvestrant complex, thereby completely inhibiting estrogen signaling through ER. Unfortunately, prolonged use of fulvestrant also leads to acquired resistance in majority of ER-positive breast cancer patients. MicroRNA microarray analysis of fulvestrant-resistant MCF-7 cells revealed downregulation of 14 miRNAs and upregulation of miR-221 and miR-222 compared to fulvestrant-sensitive parental MCF-7 cells (89). Computational analysis revealed that these downregulated miRNAs have the potential to affect 13 different pathways, including TGF- $\beta$, Wnt, MAPK signaling, and mTOR pathways that are altered in fulvestrant-resistant cell line. Detailed analysis of the role of miR-221/222 in conferring resistance to fulvestrant revealed the importance of these two miRNAs in cell cycle progression and cell proliferation. Global gene expression profiling to identify miR-221/222 target genes demonstrated deregulation of multiple oncogenic signaling pathways previously associated with drug resistance. Importantly, activation of $\beta$-catenin by miR-221/222 supported estrogen-independent growth and fulvestrant resistance whereas these two miRNAs alleviated TGF- $\beta$-mediated growth inhibition in breast cancer cells (75).

\section{Aromatase Inhibitors}

Aromatase inhibitors (AIs) are a third group of drugs that can block the growth of ER-positive tumors by inhibiting estrogen production in the body. This is predominantly used to treat postmenopausal women with ER-positive breast cancer. Letrozole, anastrazole, and exemestane are the three AIs approved by the U.S. Food and Drug Administration for treating breast cancer patients.

In women with hormone-responsive advanced breast cancer, letrozole was superior to tamoxifen in prolonging the time to disease progression and time to treatment failure as first-line therapy. It was at least as effective as anastrozole and more effective 
than megestrol as a second-line therapy (23). Differential upregulation of miR-128a is reported in letrozole resistant MCF-7 cells compared to the parental MCF-7-overexpressing aromatase gene (MCF-7aro) (62). The predicted target of human miR-128a is $3^{\prime}-$ UTR of TGBRI gene that leads to reduced levels of the TGF- $\beta$ signaling pathway. Indeed, the sensitivity to TGF- $\beta$ was compromised in the letrozole-resistant cells. The inhibition of endogenous miR-128a resulted in resensitization of the letrozole-resistant lines to TGF- $\beta$ growth inhibitory effects. It is critical to explore further the functional significance of miR128 upregulation in patients with AI-resistant breast tumor.

\section{ROLE OF MIRNAs IN RESISTANCE TO OTHER DRUGS USED IN BREAST CANCER THERAPY}

Other chemotherapeutic agents used in treating breast cancer include doxorubicin, paclitaxel, topotecan, and 5-fluorouracil. As anticipated, many patients develop resistance to these drugs as well after prolonged exposure. The expression of 84 miRNAs was significantly $(p<0.01)$ deregulated in the doxorubicin-resistant cells (47). Of these miRNAs, the expression of miR-127, miR-200a, miR-200c, miR-34a, miR-15a, miR-16, miR27b, and let-7 was significantly reduced whereas the expression of miR-21, miR-28, miR-106a, and miR-206 was elevated in the doxorubicin-resistant cells. The levels of mRNAs corresponding to BCL6, TCF8, E2F3 \& Notchl, $C Y P 1 B 1$, and $K-R A S$, which are targets of miR-127, miR-200c, miR-34a, miR-27b, and let-7, respectively, are elevated in the doxorubicin-resistant cells. On the contrary, the levels of RB1,PTEN, ER $\alpha$, and $B R C A 1$, targets of miR-106a, miR-21, miR-206, and miR-28 respectively, are much higher in the doxorubicin-sensitive MCF-7 cells, demonstrating an inverse correlation between the miRNAs and their corresponding targets in these cell lines. In addition, the expression of the miRNA processing enzymes Dicer1 and $\mathrm{AGO} 2$ was also significantly reduced in the resistant cells, which could contribute to the massive deregulation of miRNA expression observed. Further, this study showed that miR-451, which is undetectable in MCF-7/DOX cells, contributes to increased expression of multidrug resistance 1 (MDR1), thereby contributing to increased resistance to doxorubicin. Ectopic expression of miR-451 increased sensitivity of the doxorubicin-resistant cancer cells to the drug and resulted in suppression of MDR1. These studies implicate that several miRNAs function in concert when tumor develops resistance to a specific drug, which can also occur in multiple drug resistance.
Similar study with cisplatin-resistant MCF-7 cells revealed significant upregulation of miR-146a, miR$10 \mathrm{a}$, and miR-221/222 and downregulation of miR345, miR-200c, miR-126, and miR-127 (73). The expression of ZEB1/2 and MRP1, the targets of miR$200 \mathrm{c}$ and miR- 345 , respectively, was upregulated in the cisplatin-resistant cells.

Of the multiple miRNA that are deregulated in breast cancer (40), upregulation of miR-155 has been reported in several studies. Kong et al. demonstrated an inverse correlation between miR-155 and FOXO3a expression and attributed increased miR-155 expression to paclitaxel, doxorubicin, and VP16 resistance (44). In their analysis of the 77 human breast cancer specimens and 11 normal breast tissues, upregulation of $m i R-155$ was detected in 55 breast cancers and one normal breast tissue. Among the 55 tumors demonstrating elevated miR-155 level, $41(75 \%)$ had low levels of FOXO3a $(p<0.001)$. Of the 22 specimens with downregulated $m i R-155$, high levels of $F O X O 3 a$ were exhibited in 16 tumor tissues $(73 \%)$. Further analysis of miR-155 and FOXO3a levels in 38 recurrent chemo- and/or radioresistant breast cancers revealed significantly elevated miR-155 and low FOXO3a in 31 of the recurrent tumors. This finding suggests that miR-155 regulates FOXO3a expression in vivo, and that elevated level of $m i R-155$ could be a marker of chemo- and/or radioresistant breast cancer.

Using a mouse model of breast cancer where SKBR3 cells were serially passaged in NOD/SCID mice treated with epirubicin, Yu et al. demonstrated significant increase in TIC population after 3-4 passages (90). This observation was similar to that found in tumor tissues from breast cancers patients who received neoadjuvant chemotherapy compared to tumors resected from chemotherapy-naive patients (90). The expression of let-7 family of miRNAs was significantly reduced in the mammospheres compared to the parental and differentiated cells. Similarly, let-7 expression was also diminished in the TICs isolated from clinical specimens compared to the adherent cells from the same specimens irrespective of chemotherapy. These data suggest that reduced let-7 level could be an intrinsic property of TICs that is enriched upon exposure to chemotherapeutic agents.

\section{MAJOR PATHWAYS REGULATED BY THE miRNAs IN DRUG RESISTANCE}

Several pathways are affected by deregulation of miRNAs in breast cancer due to de novo or acquired resistance to common therapies. Some of these pathways could be common target of different miRNAs and multiple miRNAs could affect the same pathway 
targeting different or same protein. The effect of such miRNA deregulation is outlined below and schematically represented in Figure 1.

\section{MiR-221/222 and Regulation of Estrogen Signaling}

MiR-221/222 overexpression facilitates growth of MCF-7 cells in estrogen-free media whereas the growth of parental MCF-7 cells is retarded, showing signs of cellular damage. This estrogen-independent growth upon miR-221/222 overexpression was attributed to increased expression and activation of $\beta$ catenin (75). A direct role of $E R \alpha$ in regulating $\beta$ catenin activation or expression is not clear despite several attempts to determine possible convergence of ER $\alpha$ signaling and $\beta$-catenin pathway.

\section{MiR-221/222 and Cell Cycle Regulation}

Several studies have shown that miR-221/222 regulates cell cycle by targeting p27(Kip1), a critical in- hibitor of CDK2/cyclin complex and the closely related protein p57/Kip2. MiR-221 and miR-222 are also upregulated in aggressive prostate cancer cell lines or glioblastoma cells that contain low levels of p27 (30,31). In addition, during a screen for miRNAs capable of reducing p27 levels and increasing cell proliferative capacity Agami and colleagues (54) identified miR-221/miR-222. Stein and colleagues reported upregulation of miR-221 and miR-222 upon exit from quiescence resulting from their targeting of p27/Kip1 and p57/Kip2 (63). Further, ectopic expression of the miR-221/222 cluster activates CDK2, facilitates $\mathrm{G}_{1} / \mathrm{S}$ phase transition, and enhances tumor growth by negatively regulating p27kip1 and p57kip2.

\section{MiR-451 and Multidrug Resistance Pathway}

Activation of the MDRI (ABCBl) gene is one of the most common causes of resistance to chemotherapy. MDR1 activation leads to overexpression of Pglycoprotein (P-gp), a 170-190-kDa transmembrane

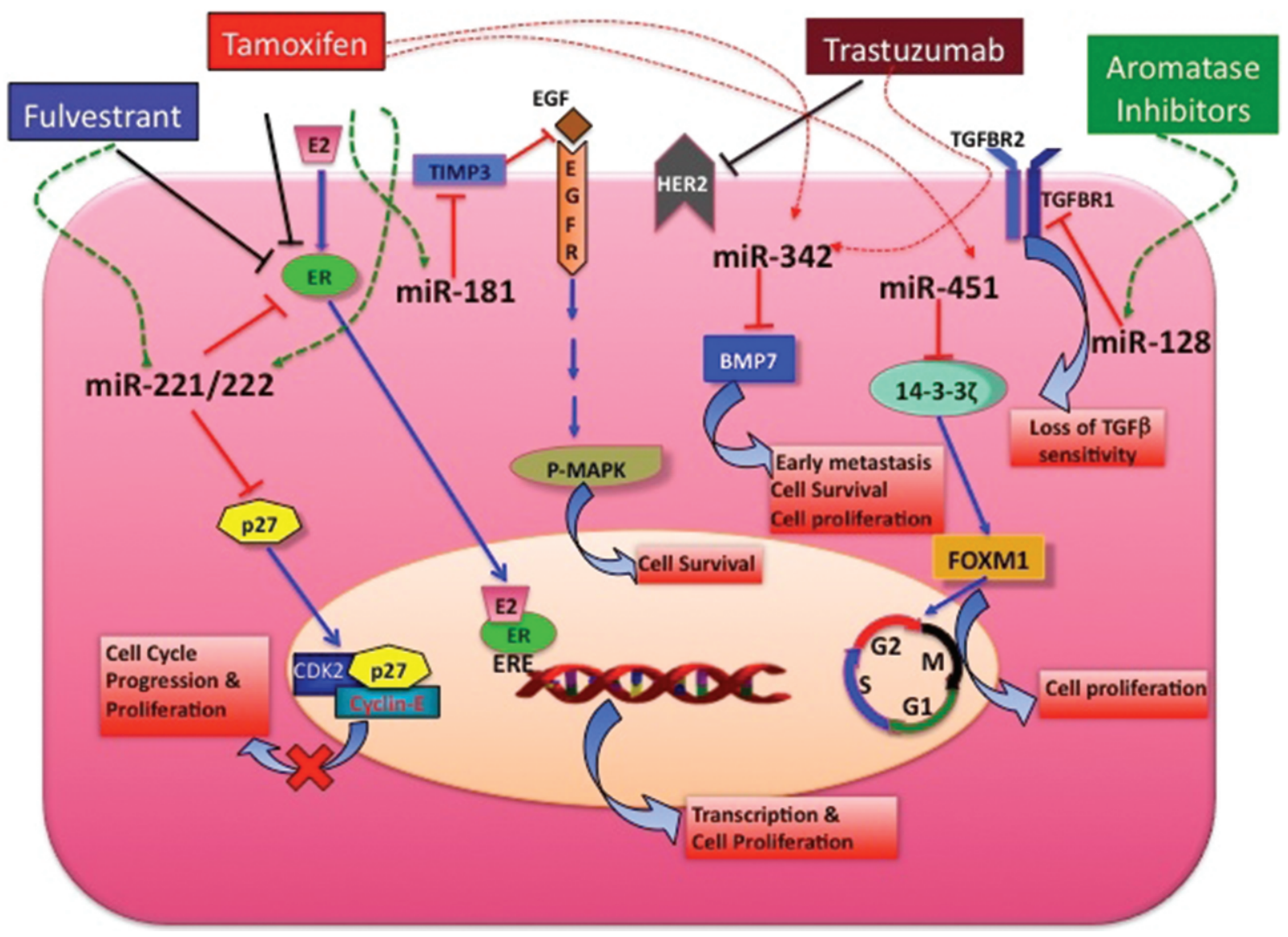

Figure 1. Several microRNAs are deregulated in endocrine-resistant breast cancer, affecting multiple signaling pathways. MicroRNAs that are up- or downregulated in response to different therapeutic agents are indicated using green and red dotted arrows, respectively. Several target genes and downstream signaling pathways affected by the deregulated genes are depicted, along with the functional implication (in red boxes). As shown here, cell proliferation, cell cycle regulation, cell survival, metastasis, and sensitivity to growth suppressors could be altered due to differential expression of miRNAs in endocrine-resistant breast cancer. 
glycoprotein that belongs to the ATP-binding cassette superfamily and acts as a multidrug transporter (32). Overexpression of $\mathrm{P}-\mathrm{gp}$ can confer resistance to a broad range of structurally and functionally diverse chemotherapeutic drugs (53). It is known that MDRI gene is induced in response to variety of chemical and physical insults by a complex set of transcriptional activation events $(1,15,17,18,38,84)$. Recent findings demonstrate that decrease in miR-451 levels in multiple drug resistant breast tumors can also cause increased expression of MDR1.

\section{MiR-200, EMT, and TICs}

Epithelial gene expression is transcriptionally suppressed during EMT, which is key to breast cancer metastasis and aggressiveness. These include members of the snail family, bHLH family, and ZFH family (ZEB1 and ZEB2) (82) proteins. Several studies have shown that miR-200 family of miRNAs inhibits translation of ZEB1 mRNA $(80,87)$ and ZEB1 suppresses the expression of all miR-200 family members (miR-141, -200a,b,c, and-429), resulting in the double-negative ZEB/miR-200 feedback loop $(11,12,34$, $45,72)$. It can be speculated that suppression of miR200 family members observed in several drug-resistant breast tumors, therefore, results in increased ZEB1 expression and facilitates EMT. These EMT activators not only enhance cellular motility, but are also involved in the maintenance of stem cell properties and cell survival $(60,66)$. Overexpression of ZEB1 in tumor cells indirectly activates expression of BMI-1, a stem cell factor, and additional targets of miR-200. Thus, inhibition of miR-200 expression in drug-resistant tumors also leads to maintenance of stem cell properties, as shown for breast and pancreatic cancer $(80,87)$.

\section{PROGNOSTIC IMPLICATIONS AND THERAPEUTIC OPTIONS}

Early detection and prediction of response to a therapeutic agent remains the greatest challenge in managing cancer patients. Several predictive genotyping tools such as OncotypeDx, MammaPrint, and PAM50 are available where the expression of a fixed set of cancer-related genes is assessed to predict sensitivity to specific treatment [reviewed in (10)]. Although this approach helps clinicians to make informed decisions about breast cancer treatment options, there is still need for additional prognostic and predictive markers to provide tailored therapy to an individual patient. Recent studies demonstrated circulating stable form of miRNAs in the serum, plasma, and packaged in microvesicles $(81,86)$, which could be noninvasive modalities for disease prediction. Unfortunately, most of the differentially expressed miRNAs reported in drug-resistant breast cancer were analyzed in cell lines exposed to the drug for prolonged period. It is therefore obvious that most of the deregulation is induced by the drug treatment and could not be used as prognostic markers. Although attempts were made in some studies to correlate differentially expressed miRNAs in drug-treated cells with those from the primary tumor biopsies obtained from patients, systematic studies to obtain a miRNA profile of primary tumors to predict drug response is warranted.

Because substantial deregulation of miRNA expression occurs in drug resistance, therapeutic strategies to modulate miRNA expression looms as a promising option to treat drug-resistant tumors or delay development of drug resistance. Use of miRNA mimics to increase expression of the downregulated miRNAs and antagomiRs to reduce the expression of overexpressed miRNAs are two direct therapeutic approaches tested both in vitro and in vivo. Use of miR mimics in cell cultures has been shown to increase the miRNA levels and suppress the specific target genes in many cancers including breast cancer cell lines. A vector-based technique using Pol III H1RNA gene promoter has also been used to achieve stable expression of miRNAs in cell cultures $(19,56)$. In addition, numerous preclinical studies have demonstrated the efficacy of recombinant adeno-associated virus (rAAV) gene delivery vectors $(3,14,46)$, and several clinical trials using these vectors are under way, showing promising results (http://regenxbio. com/nav_therapeutics/ clinical_trials). Similarly, for antagomiRs, modified oligonucleotides to resist nuclease digestion are routinely used in in vitro studies to knock down miRNAs. The modifications to protect from degradation are continuously evolving. These targeted alterations include $2^{\prime}$ - $O$-methyl, $2^{\prime}$ methoxyl modification and locked nucleic acid (LNA) antisense oligonucleotide that contains conformationally locked nucleotide monomers with a methylene bridge connecting the $2^{\prime}$-oxygen and 4 'carbon atoms of the ribose ring $(27,28,30)$. Effective suppression of miR-122 in nonhuman primate liver by systemic delivery of an unconjugated, PBS-formulated LNA-antagomiR further advances the possibility of effective antagomiR therapy in the near future (26). This technique was further modified recently and using "tiny LNA," which are 8-mer locked nucleic acid oligonucleotides targeting only the seed sequence, efficient uptake and long-term silencing of miRNAs within a family, sharing same seed sequence, was demonstrated in many normal tissues and in mouse breast tumors (70). In addition, several 
studies have now demonstrated use of adenoviral, lentiviral, or retroviral vectors expressing miRNA target sites to saturate the endogenous miRNA and prevent suppression of the target genes. This approach has been designated as microRNA decoy, sponge, or eraser $(25,77,78)$. In our recent study, direct injection of antagomiR-221/222 to tamoxifenresistant xenografts in mice caused significant reduction in miR-221/222 level and sensitization of the tumors to tamoxifen (S. Majumder, unpublished data).

\section{CONCLUSION}

In the last decade or so, miRNAs have emerged as the most powerful small molecules to regulate every aspect of cell physiology. Altered expression of specific miRNAs has enormous potential to predict treatment outcome. Nevertheless, extensive investigation in primary patient tumors with known treatment history and disease outcome is required to obtain statistically significant data to use specific miRNA as prognostic markers. Tumor biopsies from large clinical trials are valuable assets to perform such studies, as technologies to profile miRNA using miniscule amount of RNA are being explored. Further, extraordinary stability of miRNAs in serum, plasma, or microvesicles makes these small RNA molecules promising biomarkers for disease detection, prediction of response to therapy, and to monitor tumor response. The other significant advancement is the miRNA/ antimiRNA-based therapy in treating cancer patients. As outlined in this review, development of resistance to almost all commonly used drugs is associated with marked alteration in miRNA expression. Major strides have been made in miRNA therapy in the last decade. It is therefore important to evaluate combination therapy with miRNA/antimiRNA as a component to avert development of drug resistance or as an alternative to conventional therapy for recurrent disease in the future.

\section{ACKNOWLEDGMENTS}

The authors' work cited in this review article was supported in part, by the National Cancer Institute grant CA137567. We thank Dr. Bhuvaneswari Ramaswamy for critically reading this article.

\section{REFERENCES}

1. Abolhoda, A.; Wilson, A. E.; Ross, H.; Danenberg, P. V.; Burt, M.; Scotto, K. W. Rapid activation of MDR1 gene expression in human metastatic sarcoma after in vivo exposure to doxorubicin. Clin. Cancer Res. 5:3352-3356; 1999.

2. Aitken, A. 14-3-3 proteins on the MAP. Trends Biochem. Sci. 20:95-97; 1995

3. Alexander, J. J.; Hauswirth, W. W. Adeno-associated viral vectors and the retina. Adv. Exp. Med. Biol. 613: 121-128; 2008.

4. Ambros, V. The functions of animal microRNAs. Nature 431:350-355; 2004.

5. Bartel, D. P. MicroRNAs: Genomics, biogenesis, mechanism, and function. Cell 116:281-297; 2004.

6. Bartel, D. P. MicroRNAs: Target recognition and regulatory functions. Cell 136:215-233; 2009.

7. Bergamaschi, A.; Katzenellenbogen, B. S. Tamoxifen downregulation of miR-451 increases 14-3-3zeta and promotes breast cancer cell survival and endocrine resistance. Oncogene; in press.

8. Blain, S. W.; Massague, J. Breast cancer banishes p27 from nucleus. Nat. Med. 8:1076-1078; 2002.

9. Bohnsack, M. T.; Czaplinski, K.; Gorlich, D. Exportin 5 is a RanGTP-dependent dsRNA-binding protein that mediates nuclear export of pre-miRNAs. RNA 10: 185-191; 2004

10. Bonnefoi, H.; Underhill, C.; Iggo, R.; Cameron, D. Predictive signatures for chemotherapy sensitivity in breast cancer: Are they ready for use in the clinic? Eur. J. Cancer 45:1733-1743; 2009.
11. Brabletz, S.; Brabletz, T. The ZEB/miR-200 feedback loop-a motor of cellular plasticity in development and cancer? EMBO Rep. 11:670-677; 2010.

12. Burk, U.; Schubert, J.; Wellner, U.; Schmalhofer, O.; Vincan, E.; Spaderna, S.; Brabletz, T. A reciprocal repression between ZEB1 and members of the miR-200 family promotes EMT and invasion in cancer cells EMBO Rep. 9:582-589; 2008.

13. Butta, A.; MacLennan, K.; Flanders, K. C.; Sacks, N. P.; Smith, I.; McKinna, A.; Dowsett, M.; Wakefield, L. M.; Sporn, M. B.; Baum, M.; et al. Induction of transforming growth factor beta 1 in human breast cancer in vivo following tamoxifen treatment. Cancer Res. 52:42614264; 1992.

14. Chatterjee, S.; Li, W.; Wong, C. A.; Fisher-Adams, G.; Lu, D.; Guha, M.; Macer, J. A.; Forman, S. J.; Wong, Jr., K. K. Transduction of primitive human marrow and cord blood-derived hematopoietic progenitor cells with adeno-associated virus vectors. Blood 93:1882 1894; 1999

15. Chaudhary, P. M.; Roninson, I. B. Induction of multidrug resistance in human cells by transient exposure to different chemotherapeutic drugs. J. Natl. Cancer Inst. 85:632-639; 1993.

16. Chendrimada, T. P.; Gregory, R. I.; Kumaraswamy, E.; Norman, J.; Cooch, N.; Nishikura, K.; Shiekhattar, R. TRBP recruits the Dicer complex to Ago2 for microRNA processing and gene silencing. Nature 436:740$744 ; 2005$.

17. Chin, K. V.; Chauhan, S. S.; Pastan, I.; Gottesman, 
M. M. Regulation of mdr RNA levels in response to cytotoxic drugs in rodent cells. Cell Growth Differ. 1: 361-365; 1990.

18. Chin, K. V.; Tanaka, S.; Darlington, G.; Pastan, I.; Gottesman, M. M. Heat shock and arsenite increase expression of the multidrug resistance (MDR1) gene in human renal carcinoma cells. J. Biol. Chem. 265: 221-226; 1990

19. Chung, K. H.; Hart, C. C.; Al-Bassam, S.; Avery, A.; Taylor, J.; Patel, P. D.; Vojtek, A. B.; Turner, D. L. Polycistronic RNA polymerase II expression vectors for RNA interference based on BIC/miR-155. Nucleic Acids Res. 34:e53; 2006.

20. Cittelly, D. M.; Das, P. M.; Salvo, V. A.; Fonseca, J. P.; Burow, M. E.; Jones, F. E. Oncogenic HER $2 \Delta 16$ suppresses miR-15a/16 and deregulates BCL-2 to promote endocrine resistance of breast tumors. Carcinogenesis 31:2049-2057; 2010.

21. Cittelly, D. M.; Das, P. M.; Spoelstra, N. S.; Edgerton, S. M.; Richer, J. K.; Thor, A. D.; Jones, F. E. Downregulation of miR-342 is associated with tamoxifen resistant breast tumors. Mol. Cancer 9:317; 2010.

22. Colletti, R. B.; Roberts, J. D.; Devlin, J. T.; Copeland, K. C. Effect of tamoxifen on plasma insulin-like growth factor I in patients with breast cancer. Cancer Res. 49:1882-1884; 1989.

23. Dunn, C.; Keam, S. J. Letrozole: A pharmacoeconomic review of its use in postmenopausal women with breast cancer. Pharmacoeconomics 24:495-517; 2006.

24. Early Breast Cancer Trialists' Collaborative Group. Effects of chemotherapy and hormonal therapy for early breast cancer on recurrence and 15-year survival: An overview of the randomised trials. Lancet 365:16871717; 2005.

25. Ebert, M. S.; Neilson, J. R.; Sharp, P. A. MicroRNA sponges: Competitive inhibitors of small RNAs in mammalian cells. Nat. Methods 4:721-726; 2007.

26. Elmen, J.; Lindow, M.; Schutz, S.; Lawrence, M.; Petri, A.; Obad, S.; Lindholm, M.; Hedtjarn, M.; Hansen, H. F.; Berger, U.; Gullans, S.; Kearney, P.; Sarnow, P.; Straarup, E. M.; Kauppinen, S. LNA-mediated microRNA silencing in non-human primates. Nature 452 : 896-899; 2008.

27. Elmen, J.; Thonberg, H.; Ljungberg, K.; Frieden, M.; Westergaard, M.; Xu, Y.; Wahren, B.; Liang, Z.; Orum, H.; Koch, T.; Wahlestedt, C. Locked nucleic acid (LNA) mediated improvements in siRNA stability and functionality. Nucleic Acids Res. 33:439-447; 2005.

28. Esau, C.; Kang, X.; Peralta, E.; Hanson, E.; Marcusson, E. G.; Ravichandran, L. V.; Sun, Y.; Koo, S.; Perera, R. J.; Jain, R.; Dean, N. M.; Freier, S. M.; Bennett, C. F.; Lollo, B.; Griffey, R. MicroRNA-143 regulates adipocyte differentiation. J. Biol. Chem. 279: 52361-52365; 2004.

29. Frasor, J.; Chang, E. C.; Komm, B.; Lin, C. Y.; Vega, V. B.; Liu, E. T.; Miller, L. D.; Smeds, J.; Bergh, J.; Katzenellenbogen, B. S. Gene expression preferentially regulated by tamoxifen in breast cancer cells and cor- relations with clinical outcome. Cancer Res. 66:73347340; 2006.

30. Galardi, S.; Mercatelli, N.; Giorda, E.; Massalini, S.; Frajese, G. V.; Ciafre, S. A.; Farace, M. G. miR-221 and miR-222 expression affects the proliferation potential of human prostate carcinoma cell lines by targeting p27Kip1. J. Biol. Chem. 282:23716-23724; 2007.

31. Gillies, J. K.; Lorimer, I. A. Regulation of p27Kip1 by miRNA 221/222 in glioblastoma. Cell Cycle 6:20052009; 2007.

32. Gottesman, M. M.; Ling, V. The molecular basis of multidrug resistance in cancer: The early years of $\mathrm{P}$ glycoprotein research. FEBS Lett. 580:998-1009; 2006.

33. Greene, S. B.; Herschkowitz, J. I.; Rosen, J. M. Small players with big roles: MicroRNAs as targets to inhibit breast cancer progression. Curr. Drug Targets 11: 1059-1073; 2010.

34. Gregory, P. A.; Bert, A. G.; Paterson, E. L.; Barry, S. C.; Tsykin, A.; Farshid, G.; Vadas, M. A.; KhewGoodall, Y.; Goodall, G. J. The miR-200 family and miR-205 regulate epithelial to mesenchymal transition by targeting ZEB1 and SIP1. Nat. Cell Biol. 10:593$601 ; 2008$

35. Gupta, P. B.; Fillmore, C. M.; Jiang, G.; Shapira, S. D.; Tao, K.; Kuperwasser, C.; Lander, E. S. Stochastic state transitions give rise to phenotypic equilibrium in populations of cancer cells. Cell 146:633-644; 2011.

36. Hammond, S. M.; Bernstein, E.; Beach, D.; Hannon, G. J. An RNA-directed nuclease mediates post-transcriptional gene silencing in Drosophila cells. Nature 404:293-296; 2000.

37. Harris, J. R.; Morrow, M.; Bonadonna, G.; Valadi, H., editors. Cancer of the breast. Philadelphia: Lippincott; 1993.

38. Hu, Z.; Jin, S.; Scotto, K. W. Transcriptional activation of the MDR1 gene by UV irradiation. Role of NF-Y and Sp1. J. Biol. Chem. 275:2979-2985; 2000.

39. Hutvagner, G.; Zamore, P. D. A microRNA in a multiple-turnover RNAi enzyme complex. Science 297: 2056-2060; 2002.

40. Iorio, M. V.; Ferracin, M.; Liu, C. G.; Veronese, A.; Spizzo, R.; Sabbioni, S.; Magri, E.; Pedriali, M.; Fabbri, M.; Campiglio, M.; Menard, S.; Palazzo, J. P.; Rosenberg, A.; Musiani, P.; Volinia, S.; Nenci, I.; Calin, G. A.; Querzoli, P.; Negrini, M.; Croce, C. M. MicroRNA gene expression deregulation in human breast cancer. Cancer Res. 65:7065-7070; 2005.

41. Johnston, S. Fulvestrant and the sequential endocrine cascade for advanced breast cancer. Br. J. Cancer 90(Suppl. 1):S15-18; 2004.

42. Jordan, V. C. Molecular mechanisms of antiestrogen action in breast cancer. Breast Cancer Res. Treat. 31: 41-52; 1994.

43. Knabbe, C.; Lippman, M. E.; Wakefield, L. M.; Flanders, K. C.; Kasid, A.; Derynck, R.; Dickson, R. B. Evidence that transforming growth factor-beta is a hormonally regulated negative growth factor in human breast cancer cells. Cell 48:417-428; 1987. 
44. Kong, W.; He, L.; Coppola, M.; Guo, J.; Esposito, N. N.; Coppola, D.; Cheng, J. Q. MicroRNA-155 regulates cell survival, growth, and chemosensitivity by targeting FOXO3a in breast cancer. J. Biol. Chem. 285: 17869-17879; 2010.

45. Korpal, M.; Lee, E. S.; Hu, G.; Kang, Y. The miR-200 family inhibits epithelial-mesenchymal transition and cancer cell migration by direct targeting of E-cadherin transcriptional repressors ZEB1 and ZEB2. J. Biol. Chem. 283:14910-14914; 2008.

46. Kota, J.; Chivukula, R. R.; O’Donnell, K. A.; Wentzel, E. A.; Montgomery, C. L.; Hwang, H. W.; Chang, T. C.; Vivekanandan, P.; Torbenson, M.; Clark, K. R.; Mendell, J. R.; Mendell, J. T. Therapeutic microRNA delivery suppresses tumorigenesis in a murine liver cancer model. Cell 137:1005-1017; 2009.

47. Kovalchuk, O.; Filkowski, J.; Meservy, J.; Ilnytskyy, Y.; Tryndyak, V. P.; Chekhun, V. F.; Pogribny, I. P. Involvement of microRNA-451 in resistance of the MCF-7 breast cancer cells to chemotherapeutic drug doxorubicin. Mol. Cancer Ther. 7:2152-2159; 2008.

48. Kozomara, A.; Griffiths-Jones, S. miRBase: Integrating microRNA annotation and deep-sequencing data. Nucleic Acids Res. 39:D152-157; 2011.

49. Lacerda, L.; Pusztai, L.; Woodward, W. A. The role of tumor initiating cells in drug resistance of breast cancer: Implications for future therapeutic approaches. Drug Resist. Updat. 13:99-108;

50. Landthaler, M.; Yalcin, A.; Tuschl, T. The human DiGeorge syndrome critical region gene 8 and Its D. melanogaster homolog are required for miRNA biogenesis. Curr. Biol. 14:2162-2167; 2004.

51. Lee, Y.; Ahn, C.; Han, J.; Choi, H.; Kim, J.; Yim, J.; Lee, J.; Provost, P.; Radmark, O.; Kim, S.; Kim, V. N. The nuclear RNase III Drosha initiates microRNA processing. Nature 425:415-419; 2003.

52. Lee, Y.; Kim, M.; Han, J.; Yeom, K. H.; Lee, S.; Baek, S. H.; Kim, V. N. MicroRNA genes are transcribed by RNA polymerase II. EMBO J. 23:4051-4060; 2004.

53. Leonard, G. D.; Fojo, T.; Bates, S. E. The role of ABC transporters in clinical practice. Oncologist 8:411-424; 2003.

54. le Sage, C.; Nagel, R.; Egan, D. A.; Schrier, M.; Mesman, E.; Mangiola, A.; Anile, C.; Maira, G.; Mercatelli, N.; Ciafre, S. A.; Farace, M. G.; Agami, R. Regulation of the $\mathrm{p} 27$ (Kip1) tumor suppressor by miR-221 and miR222 promotes cancer cell proliferation. EMBO J. 26: 3699-3708; 2007.

55. Lewis, J. S.; Jordan, V. C. Selective estrogen receptor modulators (SERMs): Mechanisms of anticarcinogenesis and drug resistance. Mutat. Res. 591:247-263; 2005.

56. Liang, Z.; Wu, H.; Reddy, S.; Zhu, A.; Wang, S.; Blevins, D.; Yoon, Y.; Zhang, Y.; Shim, H. Blockade of invasion and metastasis of breast cancer cells via targeting CXCR4 with an artificial microRNA. Biochem. Biophys. Res. Commun. 363:542-546; 2007.

57. Lim, L. P.; Lau, N. C.; Garrett-Engele, P.; Grimson, A.; Schelter, J. M.; Castle, J.; Bartel, D. P.; Linsley, P. S.; Johnson, J. M. Microarray analysis shows that some microRNAs downregulate large numbers of target mRNAs. Nature 433:769-773; 2005.

58. Lonning, P. E. Molecular basis for therapy resistance. Mol. Oncol. 4:284-300; 2010.

59. Maillot, G.; Lacroix-Triki, M.; Pierredon, S.; Gratadou, L.; Schmidt, S.; Benes, V.; Roche, H.; Dalenc, F.; Auboeuf, D.; Millevoi, S.; Vagner, S. Widespread estrogen-dependent repression of micrornas involved in breast tumor cell growth. Cancer Res. 69:83328340; 2009.

60. Mani, S. A.; Guo, W.; Liao, M. J.; Eaton, E. N.; Ayyanan, A.; Zhou, A. Y.; Brooks, M.; Reinhard, F.; Zhang, C. C.; Shipitsin, M.; Campbell, L. L.; Polyak, K.; Brisken, C.; Yang, J.; Weinberg, R. A. The epithelialmesenchymal transition generates cells with properties of stem cells. Cell 133:704-715; 2008.

61. Martinez, J.; Patkaniowska, A.; Urlaub, H.; Luhrmann, R.; Tuschl, T. Single-stranded antisense siRNAs guide target RNA cleavage in RNAi. Cell 110:563-574; 2002.

62. Masri, S.; Liu, Z.; Phung, S.; Wang, E.; Yuan, Y. C.; Chen, $\mathrm{S}$. The role of microRNA-128a in regulating TGFbeta signaling in letrozole-resistant breast cancer cells. Breast Cancer Res. Treat. 124:89-99; 2010.

63. Medina, R.; Zaidi, S. K.; Liu, C. G.; Stein, J. L.; van Wijnen, A. J.; Croce, C. M.; Stein, G. S. MicroRNAs 221 and 222 bypass quiescence and compromise cell survival. Cancer Res. 68:2773-2780; 2008.

64. Miller, T. E.; Ghoshal, K.; Ramaswamy, B.; Roy, S.; Datta, J.; Shapiro, C. L.; Jacob, S.; Majumder, S. MicroRNA-221/222 confers tamoxifen resistance in breast cancer by targeting p27Kip1. J. Biol. Chem. 283:29897-29903; 2008.

65. Mitra, D.; Brumlik, M. J.; Okamgba, S. U.; Zhu, Y.; Duplessis, T. T.; Parvani, J. G.; Lesko, S. M.; Brogi, E.; Jones, F. E. An oncogenic isoform of HER2 associated with locally disseminated breast cancer and trastuzumab resistance. Mol. Cancer Ther. 8:2152-2162; 2009.

66. Morel, A. P.; Lievre, M.; Thomas, C.; Hinkal, G.; Ansieau, S.; Puisieux, A. Generation of breast cancer stem cells through epithelial-mesenchymal transition. PLoS One 3:e2888; 2008.

67. Musgrove, E. A.; Sutherland, R. L. Biological determinants of endocrine resistance in breast cancer. Nat. Rev. Cancer 9:631-643; 2009.

68. Naresh, A.; Thor, A. D.; Edgerton, S. M.; Torkko, K. C.; Kumar, R.; Jones, F. E. The HER4/4ICD estrogen receptor coactivator and $\mathrm{BH} 3$-only protein is an effector of tamoxifen-induced apoptosis. Cancer Res. 68:6387-6395; 2008.

69. Nowell, P. C. The clonal evolution of tumor cell populations. Science 194:23-28; 1976.

70. Obad, S.; dos Santos, C. O.; Petri, A.; Heidenblad, M.; Broom, O.; Ruse, C.; Fu, C.; Lindow, M.; Stenvang, J.; Straarup, E. M.; Hansen, H. F.; Koch, T.; Pappin, D.; Hannon, G. J.; Kauppinen, S. Silencing of microRNA families by seed-targeting tiny LNAs. Nat. Genet. 43:371-378; 2011.

71. Osborne, C. K.; Schiff, R. Mechanisms of endocrine 
resistance in breast cancer. Annu. Rev. Med. 62:233247; 2011.

72. Park, S. M.; Gaur, A. B.; Lengyel, E.; Peter, M. E. The miR-200 family determines the epithelial phenotype of cancer cells by targeting the E-cadherin repressors ZEB1 and ZEB2. Genes Dev. 22:894-907; 2008.

73. Pogribny, I. P.; Filkowski, J. N.; Tryndyak, V. P.; Golubov, A.; Shpyleva, S. I.; Kovalchuk, O. Alterations of microRNAs and their targets are associated with acquired resistance of MCF-7 breast cancer cells to cisplatin. Int. J. Cancer 127:1785-1794; 2010.

74. Pusztai, L.; Hortobagyi, G. N. High-dose chemotherapy: How resistant is breast cancer? Drug Resist. Updat. 1: 62-72; 1998.

75. Rao, X.; Di Leva, G.; Li, M.; Fang, F.; Devlin, C.; Hartman-Frey, C.; Burow, M. E.; Ivan, M.; Croce, C. M.; Nephew, K. P. MicroRNA-221/222 confers breast cancer fulvestrant resistance by regulating multiple signaling pathways. Oncogene 30:1082-1097; 2010.

76. Rodriguez, A.; Griffiths-Jones, S.; Ashurst, J. L.; Bradley, A. Identification of mammalian microRNA host genes and transcription units. Genome Res. 14:19021910; 2004.

77. Sayed, D.; Rane, S.; Lypowy, J.; He, M.; Chen, I. Y.; Vashistha, H.; Yan, L.; Malhotra, A.; Vatner, D.; Abdellatif, M. MicroRNA-21 targets Sprouty2 and promotes cellular outgrowths. Mol. Biol. Cell 19: 3272-3282; 2008.

78. Scherr, M.; Venturini, L.; Battmer, K.; Schaller-Schoenitz, M.; Schaefer, D.; Dallmann, I.; Ganser, A.; Eder, M. Lentivirus-mediated antagomir expression for specific inhibition of miRNA function. Nucleic Acids Res. 35:e149; 2007.

79. Shi, W.; Gerster, K.; Alajez, N. M.; Tsang, J.; Waldron, L.; Pintilie, M.; Hui, A. B.; Sykes, J.; P'ng, C.; Miller, N.; McCready, D.; Fyles, A.; Liu, F. F. MicroRNA301 mediates proliferation and invasion in human breast cancer. Cancer Res. 71:2926-2937; 2011.

80. Shimono, Y.; Zabala, M.; Cho, R. W.; Lobo, N.; Dalerba, P.; Qian, D.; Diehn, M.; Liu, H.; Panula, S. P.; Chiao, E.; Dirbas, F. M.; Somlo, G.; Pera, R. A.; Lao, K.; Clarke, M. F. Downregulation of miRNA200c links breast cancer stem cells with normal stem cells. Cell 138:592-603; 2009.

81. Skog, J.; Wurdinger, T.; van Rijn, S.; Meijer, D. H.; Gainche, L.; Sena-Esteves, M.; Curry, Jr., W. T.; Carter, B. S.; Krichevsky, A. M.; Breakefield, X. O.
Glioblastoma microvesicles transport RNA and proteins that promote tumour growth and provide diagnostic biomarkers. Nat. Cell Biol. 10:1470-1476; 2008.

82. Thiery, J. P.; Acloque, H.; Huang, R. Y.; Nieto, M. A. Epithelial-mesenchymal transitions in development and disease. Cell 139:871-890; 2009.

83. Tzivion, G.; Avruch, J. 14-3-3 proteins: Active cofactors in cellular regulation by serine/threonine phosphorylation. J. Biol. Chem. 277:3061-3064; 2002.

84. Uchiumi, T.; Kohno, K.; Tanimura, H.; Matsuo, K.; Sato, S.; Uchida, Y.; Kuwano, M. Enhanced expression of the human multidrug resistance 1 gene in response to UV light irradiation. Cell Growth Differ. 4: 147-157; 1993.

85. Uhr, J. W.; Scheuermann, R. H.; Street, N. E.; Vitetta, E. S. Cancer dormancy: Opportunities for new therapeutic approaches. Nat. Med. 3:505-509; 1997.

86. Valadi, H.; Ekstrom, K.; Bossios, A.; Sjostrand, M.; Lee, J. J.; Lotvall, J. O. Exosome-mediated transfer of mRNAs and microRNAs is a novel mechanism of genetic exchange between cells. Nat. Cell Biol. 9:654659; 2007

87. Wellner, U.; Schubert, J.; Burk, U. C.; Schmalhofer, O.; Zhu, F.; Sonntag, A.; Waldvogel, B.; Vannier, C.; Darling, D.; zur Hausen, A.; Brunton, V. G.; Morton, J.; Sansom, O.; Schuler, J.; Stemmler, M. P.; Herzberger, C.; Hopt, U.; Keck, T.; Brabletz, S.; Brabletz, T. The EMT-activator ZEB1 promotes tumorigenicity by repressing stemness-inhibiting microRNAs. Nat. Cell Biol. 11:1487-1495; 2009.

88. Wright, J. A.; Richer, J. K.; Goodall, G. J. microRNAs and EMT in mammary cells and breast cancer. J. Mammary Gland Biol. Neoplasia 15:213-223; 2010.

89. Xin, F.; Li, M.; Balch, C.; Thomson, M.; Fan, M.; Liu, Y.; Hammond, S. M.; Kim, S.; Nephew, K. P. Computational analysis of microRNA profiles and their target genes suggests significant involvement in breast cancer antiestrogen resistance. Bioinformatics 25:430-434; 2009.

90. Yu, F.; Yao, H.; Zhu, P.; Zhang, X.; Pan, Q.; Gong, C.; Huang, Y.; Hu, X.; Su, F.; Lieberman, J.; Song, E. let-7 regulates self renewal and tumorigenicity of breast cancer cells. Cell 131:1109-1123; 2007.

91. Zhao, J. J.; Lin, J.; Yang, H.; Kong, W.; He, L.; Ma, X.; Coppola, D.; Cheng, J. Q. MicroRNA-221/222 negatively regulates estrogen receptor alpha and is associated with tamoxifen resistance in breast cancer. J. Biol. Chem. 283:31079-31086; 2008. 